\title{
Tobacco Use Prevention Research
}

National Cancer Institute

\section{Source}

National Cancer Institute. Tobacco Use Prevention Research. NCI Thesaurus. Code C16211.

Studies to develop and test interventions that are designed to prevent the initiation of tobacco use among individuals. ( $\mathrm{NCI} / \mathrm{TRIP}$ ) 